Fifth International Conference on Sustainable Construction Materials and Technologies. http://www.claisse.info/Proceedings.htm

\title{
EFFECTIVE BRIDGE MAINTENANCE BASED ON LOAD-BEARING PERFORMANCE SIMPLE EVALUATION
}

\author{
Hitoshi Ito ${ }^{1}$, Toshiaki Mizobuchi ${ }^{2}$ \\ ${ }^{1}$ 5-20-8, Asakusabashi, Taito Ward, Tokyo, Japan, e-mail: ht-ito@ yachiyo-eng.co.jp, \\ Yachiyo Engineering Co., Ltd., Structure \& Bridge Department. \\ 2 3-7-2, Kajino-cho, Koganei-shi, Tokyo, Japan, e-mail: mizobuch@ hosei.ac.jp, Hosei \\ University.
}

\begin{abstract}
Structural performances (load-bearing performance) of RC road bridges descend by the deterioration of reinforcing bars. Municipalities in Japan, that manage the majority of bridges, have many bridges in need of maintenance, but budget and human resources are limited. Therefore, in this paper, for small bridges managed by municipalities, we construct the method of effective and sustainable maintenance work using evaluation result of the structural condition by simple method. The structural condition evaluation of bridges focus on simplicity in order to apply to a large number of bridges than precision. This method evaluates structural performance by obtaining deterioration data from the representative bridge by non-destructive testing. This system does not require a lot of cost and time, because of the less amount workload of survey and analysis, it is possible to periodically update the assessment results.
\end{abstract}

Keywords: Monitoring of structural soundness, Non-destructive method, Structural performance Simple evaluation, Prediction of deterioration progression

\section{INTRODUCTION}

\section{Problem of Bridge Maintenance}

In Japan, bridge administrators should implement effective maintenance, in order to keep bridges in good conditions, because safety of bridges degrade when bridges have deterioration. Structural performance (load-bearing performance) of RC road bridges descend by the deterioration of reinforcing bars, and the passage of some bridges have been restricted. MLIT (Ministry of Land, Infrastructure, Transport and Tourism) reported that the number of passage restricted bridges and maintenance cost increases, as the number of aging bridge increases in the future. In addition, human resources of maintenance work have been decreasing. Therefore, the shortage of budget and time 
are problems in the bridge maintenance. As the result, administrator of bridges require the method for reducing the maintenance cost and improving the efficiency.

\section{Situation of Municipalities In Japan}

Municipalities that manage the majority of bridges in Japan have many bridges in need of maintenance, but budget and human resources are limited. Therefore, the problem of bridge maintenances is bigger than other administrators. Table 1 shows grades of bridge condition in the inspection. Administrators will plan repair of grade G3 or G4 bridges. However, municipalities do inspection but they do not repair works enough. Table 2 shows progression of repair works. In the past three years, $87 \%$ of grade G3 or G4 bridges have not been repaired. In general procedure, administrators do detail investigations and repair works after inspections, but administrators in municipalities cannot do it. On the other hand, the deterioration situation of the bridge judged as grade G3, G4 are not uniform. Even in bridges judged as grade G3 and G4, the degradation of bridge safety are some case of serious degree but some case is slight degree. Because the degradation of bridge safety depends on range and degree of deterioration. Therefore, it is not necessary to uniformly repair all bridges judged grade G3, G4, and the introduction of preventive maintenance, observation maintenance, and considering priority of repair are effective.

\section{The Monitoring of Structural Soundness}

The preventive maintenance and the observation maintenance requires judgment of appropriate repair time. For that purpose, degradation information in an entire bridge, the prediction of progression from the early stage of deterioration, monitoring of structural soundness are necessary. In other words, the monitoring of structural soundness from early stage of degradation is effective to do the preventive maintenance and the observation maintenance. Thus, in this paper, we will construct a method to monitor the structural safety of bridges from the beginning of deterioration. The target structure of this paper is a small-scale bridge deteriorated by salt damage (rapidly progressing deterioration) managed by municipalities. The method does not require cost and time for data collection, analysis and update, for continuous implementation. We define it as the "simple" structural performance evaluation system.

Table 1 . The bridge condition grade

\begin{tabular}{c|l||l}
\hline \multicolumn{2}{c|}{ Condition Grade } & \multicolumn{1}{c}{ General condition guideline } \\
\hline \hline G1 & Good & The bridge have no problem with the function \\
\hline G2 & Precautionary stage & $\begin{array}{l}\text { The bridge have no problem with the function, but } \\
\text { the bridge requires countermeasure for prevention }\end{array}$ \\
\hline G3 & Countermeasure stage & $\begin{array}{l}\text { The bridge have problem with the function, and the } \\
\text { bridge requires early countermeasure }\end{array}$ \\
\hline G4 & Emergency stage & $\begin{array}{l}\text { The bridge have problem with the function, and the } \\
\text { bridge requires emergency countermeasure }\end{array}$ \\
\hline
\end{tabular}


Table 2. Progression of repair works of bridges in municipalities (number of bridges)

\begin{tabular}{c||r||r|r|r|r|r|r}
\hline \multirow{2}{*}{ Year } & \multirow{2}{*}{$\begin{array}{c}\text { Inspected } \\
\text { bridge }\end{array}$} & \multicolumn{6}{|c}{ Progression of repair works } \\
\cline { 3 - 8 } & & \multicolumn{2}{|c|}{ Condition Grade G3, G4 } & \multicolumn{3}{c}{ Condition Grade G2 } \\
\cline { 3 - 8 } & & Target & Completion & Ratio & Target & Completion & Ratio \\
\hline 2014 & 32,451 & 5,130 & 1,064 & 0.21 & 15,840 & no data & \\
\hline 2015 & 92,522 & 9,550 & 1,223 & 0.13 & 47,701 & no data & \\
\hline 2016 & 133,696 & 12,051 & 1,089 & 0.09 & 64,507 & no data & \\
\hline \hline Total & 258,669 & 26,731 & 3,376 & 0.13 & 128,048 & 2,413 & 0.02 \\
\hline
\end{tabular}

\section{THE MAINTENANCE OF SALT DAMAGED BRIDGE}

\section{Performance Requirements of Bridges}

Performance requirements of the bridge maintenance are safety, serviceability, restorability and durability. Among them, the safety is important for administrators, but methods to evaluate aging variation of the safety have been not sufficient yet. In the case of salt damage, the safety of bridge degrades with the reduction of cross section of reinforcing bars as a result of corrosion due to permeation of chloride ions. In addition, the cracking, the swelling, peeling will appear with the reduction of cross section of reinforcing bars. Therefore, the variation of structural safety of salt damaged bridge can be monitored by periodically investigating appearance, penetration of chloride ions, and corrosion status of reinforcing bars. However, the conventional method cannot do continuously monitoring from the early stage of deterioration in an entire bridge.

\section{Distribution Investigation of Salt Damage}

There are various methods for investigating the existing structure on salt damage, but cost is different for each investigation (Figure 1). Many conventional method are focused on the accuracy of the obtained data. In this paper, we apply low cost investigation methods (chloride ion amounts investigation by electromagnetic wave radar method and fluorescent X-ray method, etc.), because we will collect a lot of data. Watanabe et al proposed the method of chloride ion investigation by fluorescent $\mathrm{X}$ ray. The procedure of this method is follow. We collect concrete powder from existing structure with a drill (diameter $=20 \mathrm{~mm}$ ) every $1 \mathrm{~cm}$ depth. Next, we measure chloride ion amounts by X-ray fluorescence. Finally we convert measured ppm value to chloride ion amounts using formula proposed by Watanabe et al. Nojima et al proposed the method of chloride ion investigation by electromagnetic wave radar. This method evaluate chloride ion amounts from the electromagnetic wave data measured on the surface of the structure. The distribution of chloride ion penetration is easily evaluated by combining these methods. In addition, the method using mortar pieces can evaluate the tendency of salt damage in the area. These methods are effective in investigation of bridges in municipalities where budget and time are not sufficient. 


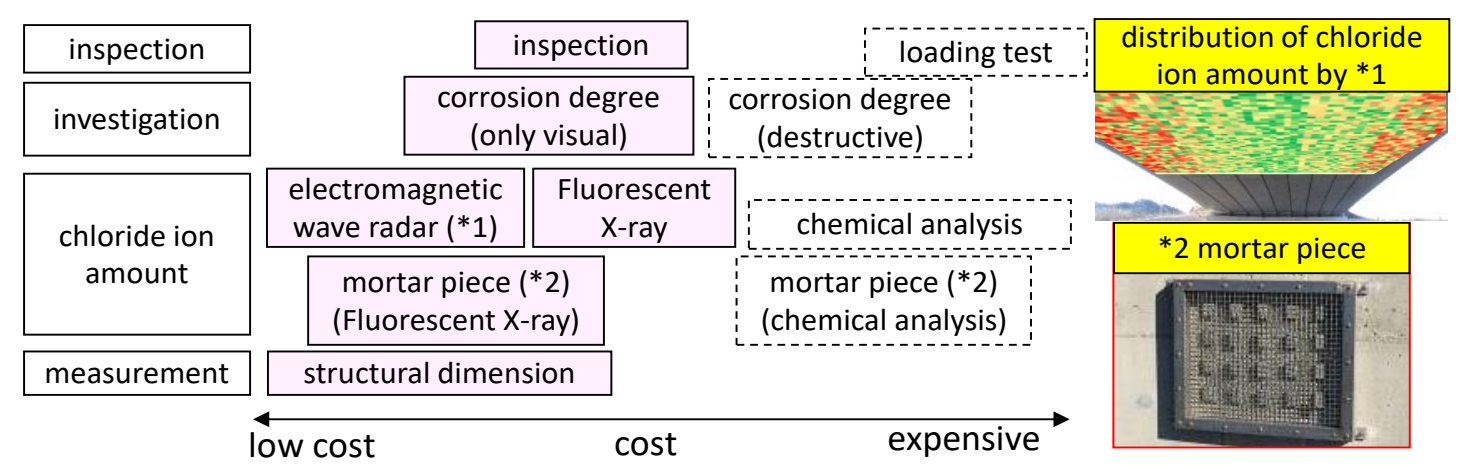

Figure 1. Cost of investigation

\section{Monitoring of Salt Damage Progression}

The variation of structural safety of salt damaged bridge can be monitored by periodically investigating appearance, penetration of chloride ions, and corrosion status of reinforcing bars. The method I described before can evaluate easily chloride ion penetration and distribution. However, administrators do not apply these method to do monitoring about the structural safety from early stage of deterioration. The reasons are as follows. Therefore, in this paper, we construct a structural performance simple evaluation system that evaluates structural safety with non-destruction, as a method for monitoring structural safety of bridges.

\section{STRUCTURAL EVALUATION SYSTEM WITH NON-DESTRUCTION}

\section{Simple Evaluation System of Structural Performance}

It is possible to calculate the structural performance with high accuracy by carrying out enough surveys and analysing the condition using an elaborated model. Investigation of corrosion amount of reinforcing bars (with some destruction) and analysis evaluate structural performance with high accuracy. However, this method requires cost and time, in addition to the influence on the structure. Therefore, the structural performance simple evaluation system evaluates the structural performance with non-destructive (= no investigation of corrosion amount of reinforcing bars). The evaluation result of this method has range (not specific value), but it can be applied to many bridges. This system does not apply no quantitative data on corrosion amount of reinforcing bars. As a result, the evaluation result includes inevitably uncertainly. Therefore, we apply applies probability evaluation (Monte Carlo method) to this system for evaluating uncertainly. Figure 2 shows the procedure. 


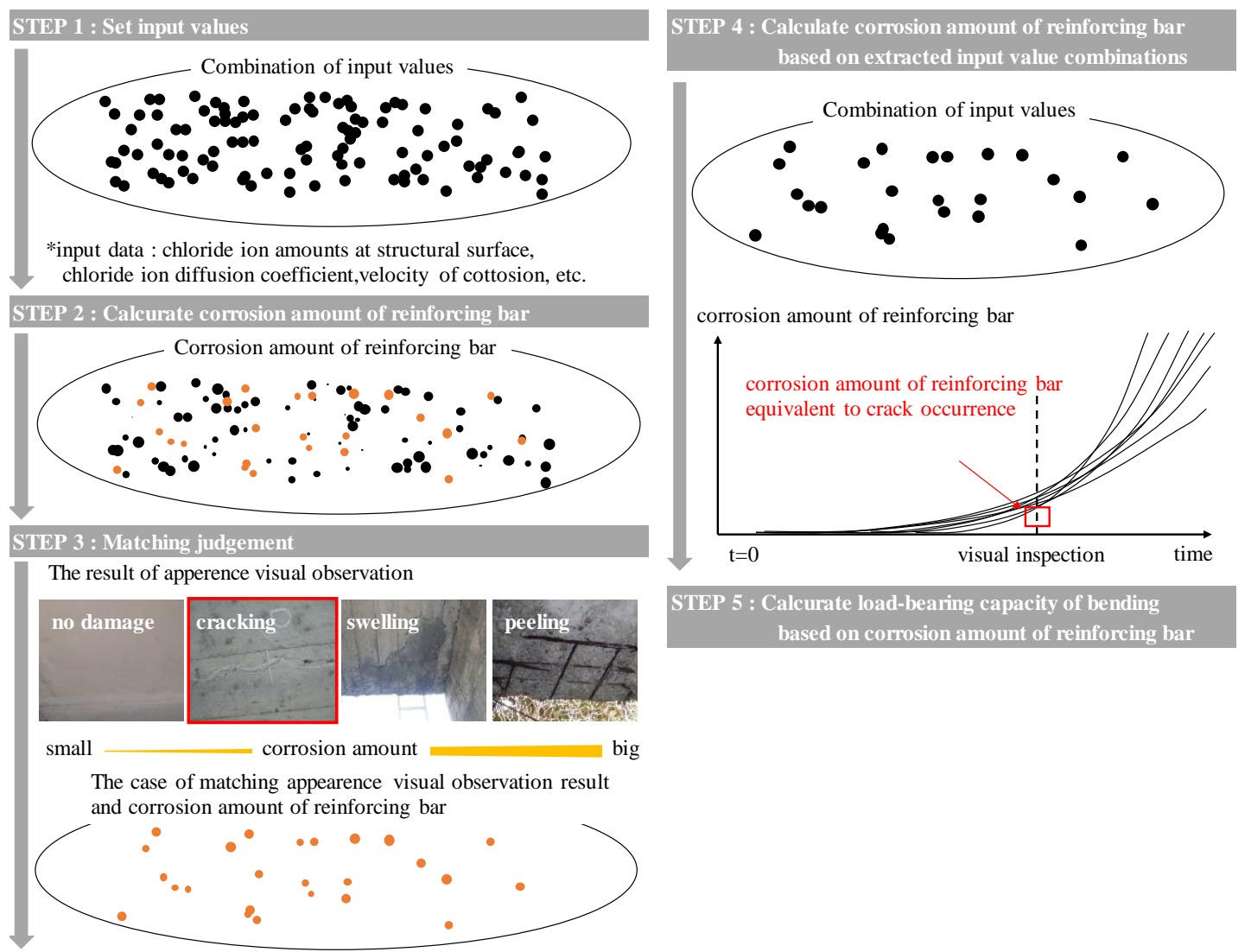

Figure 2. The procedure of the system 


\section{The System Procedure}

We set the steel corrosion conditions, material conditions and structural conditions in multiple cases (as condition group) using random variable (STEP 1). Each condition group has time variation of different corrosion amount of reinforcing bars (STEP 2). As the corrosion amount of reinforcing bar increases, the appearance change is caused (cracking, swelling, peeling, etc.). That is, the amount of corrosion of reinforcing bars is related to the appearance visual observation result. Therefore, condition groups that corrosion amount of reinforcing bar matches visual observation result are selected from the corrosion conditions of reinforcing bars calculated at STEP 2 (STEP 3). Next, we set the selected condition groups as steel corrosion conditions of the target bridge (STEP 4), and we calculate load baring capacity of the target bridge based on corrosion amount of reinforcing bars set in STEP 4 (STEP 5). Although this is an estimation and not a specific value but a range, we can evaluate structural safety in the current and future with non-destruction. In addition, the estimation result of corrosion amount can predict damage progression.

\section{LOAD-BEARING CAPACITY OF BENDING}

\section{Introduction}

In the structural performance simplified evaluation system, it is important to match calculation result of corrosion amount of reinforcing bar and appearance visual observation result. Therefore, the calculation method of corrosion amount of reinforcing bar and the calculation method of load-bearing capacity of bending do not have big influence to the system. In this paper, we apply random variables (Table 3) and calculation method of corrosion amount of reinforcing bar that is the method of Kinoshita et al applied to structures in salt damage environment. We calculate loadbearing capacity of bending as an ultimate bending moment based on the method of Japan road association. This method is widely applied to the evaluation of load-bearing capacity of municipal bridges. According to the results of the research at Japan Society of Civil Engineers (JSCE), in the case of salt damage, the reduction of cross section of reinforcing bar is related in steel performance changing. Therefore, in the case of calculating load-bearing capacity of bending of reinforced concrete member, we evaluate load-bearing capacity changing due to deterioration by considering the cross section changing of reinforcing bar.

Table 3: Random variable

\begin{tabular}{l|c||c|c|c|c}
\hline \multicolumn{1}{c|}{ Random variable } & & $\begin{array}{c}\text { Probability } \\
\text { distribution }\end{array}$ & Average & $\begin{array}{c}\text { Coefficient } \\
\text { of variation }\end{array}$ & $\begin{array}{c}\text { Standard } \\
\text { deviation }\end{array}$ \\
\hline $\begin{array}{l}\text { Chloride ion concentration } \\
\text { for the corrosion occurence }\end{array}$ & $x_{1}$ & uniform & 1.0 & 0.20 & 0.20 \\
\hline $\begin{array}{l}\text { Corrosion amount for the } \\
\text { occurence of crack }\end{array}$ & $x_{2}$ & $\log$ normal & 1.00 & 0.330 & 0.330 \\
\hline $\begin{array}{l}\text { Compressive strength } \\
\begin{array}{l}\text { Velocity of corrosion before } \\
\text { the occurence of crack }\end{array}\end{array}$ & $x_{3}$ & normal & 1.00 & 0.0382 & 0.0382 \\
\hline
\end{tabular}


Velocity of corrosion after the occurence of crack 


\section{Corrosion Beginning Point of Reinforcing Bar}

Corrosion beginning point of reinforcing bar is defined as the time when the amount of chloride ion amount at the surface of reinforcing bar exceeds the corrosion limit chloride ion amount.

$$
\begin{aligned}
& \mathrm{C}=C_{o}\left\{1-\operatorname{erf} \frac{0.1 c}{2 \sqrt{D t}}\right\}+C_{i} \\
& C_{\text {lim }}=x_{1} \times 2.12
\end{aligned}
$$

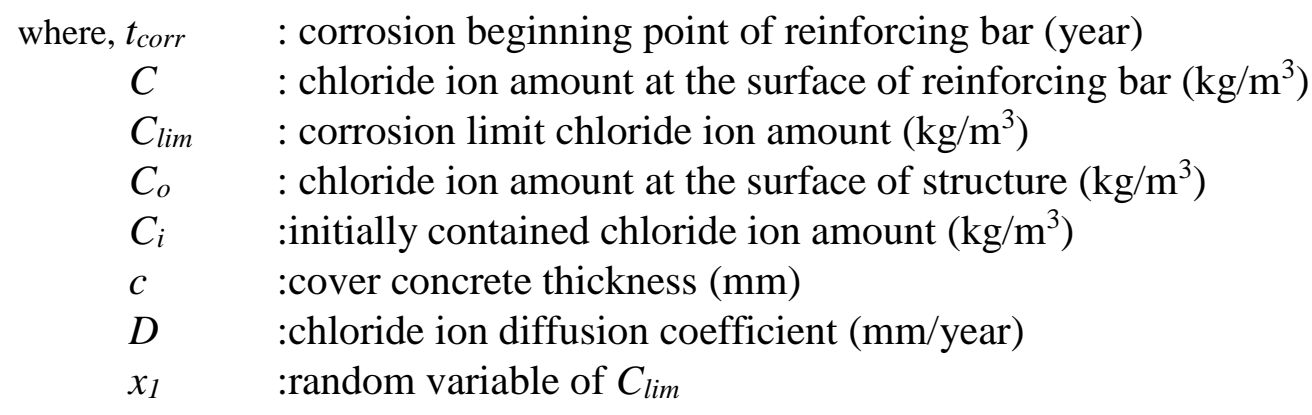

\section{Cracking Occurrence Point}

Cracking occurrence point is defined as the time when the corrosion amount of reinforcing bar exceeds cracking occurrence limit corrosion amount. We apply the estimation formula proposed by Qi to calculate corrosion amount. The applicable value of Kinoshita et al are shown in parentheses.

$$
\begin{aligned}
& t_{c r}=t_{c o r r}+\frac{x_{2} \eta W_{c}}{x_{4} V_{b}} \\
& W_{c}=\frac{100 \rho_{s}}{\pi(\gamma-1)}\left[\alpha_{0} \beta_{0} \frac{0.22\left[(2 c+\varphi)^{2}+\varphi^{2}\right]^{\frac{2}{3}}}{E_{c}(c+\varphi)}+\left(x_{3} f_{c}^{\prime}\right)+\alpha_{1} \beta_{1} \frac{c+\varphi}{5 c+3 \varphi} w_{c r}\right]
\end{aligned}
$$




$$
\begin{aligned}
& \beta_{0}=-0.0055 x_{3} f_{c}^{\prime}+1.07 \\
& \alpha_{1}=(0.0007 \varphi-0.04) c+(0.0663 \varphi+5.92) \\
& \beta_{1}=-0.0016 x_{3} f_{c}^{\prime}+1.04
\end{aligned}
$$

\section{Reduction Amount of Reinforcing Bar}

Reduction amount of reinforcing bar is calculated by the following equation. The applicable value of Kinoshita et al are shown in parentheses.

$$
\begin{aligned}
& A s_{\text {red }}=A s \times \omega \\
& \text { Corrosion amount } \\
& \quad \text { before beginning corrosion } Q=0 \\
& \quad \text { from beginning corrosion to before occurring crack } Q=x_{4} \cdot V_{b} \cdot\left(t-t_{c o r r}\right) \\
& \quad \text { after occurring crack } Q=x_{4} \cdot V_{b} \cdot\left(t_{c r}-t_{c o r r}\right)+x_{5} \cdot V_{a} \cdot\left(t-t_{c r}\right) \\
& \text { ratio of mass reduction } \omega=\frac{Q}{\rho \varphi / 4 \times 100}
\end{aligned}
$$

where, $A s_{\text {red }}:$ Reduction amount of reinforcing $\operatorname{bar}\left(\mathrm{cm}^{2}\right)$

$V_{a}$ :velocity of corrosion after cracking occurrence ( $\mathrm{mg} / \mathrm{cm}^{2} /$ year) [50.3]

As :initial cross-sectional area of reinforcing bar $\left(\mathrm{cm}^{2}\right)$

$x_{5} \quad$ :random variable of $V_{a}$

\section{Matching Judgement}

Matching judgement of the appearance condition and cross-sectional area of reinforcing bar is based on Table 4 . We select condition groups that corrosion amount of reinforcing bar matches visual observation result. Regarding peeling, it is set as an assumed value, because it is not a damage in initiation period and propagation period targeting in this paper.

Table 4. Appearance condition and reduction in cross section of reinforcing bar

\begin{tabular}{l|l}
\hline the appearance condition & \multicolumn{1}{|c}{ Reduction of cross-sectional area of reinforcing bar } \\
\hline No & less than $A s \cdot W_{d} /(\varphi \rho / 4 \cdot 100)$ \\
\hline Cracking & more than $A s \cdot W_{d} /(\varphi \rho / 4 \cdot 100)$ and less than $A s \cdot 0.2$ \\
\hline Swelling, Peeling & more than $A s \cdot 0.2$ \\
\hline
\end{tabular}

\section{APPLICATION TO EXISTING STRUCTURE}

\section{Target Structure}

The target area has a temperate climate with an average annual temperature of $16^{\circ} \mathrm{C}$ or more, and two sides of this area face the sea. Many citizens live in the coastal area, therefore coastal roads are important for them. Target structures is the simple slab bridge located $50 \mathrm{~m}$ from coastal line in this area. Table 4 shows bridge conditions.

Table 5: Bridge condition

Bridge No




\begin{tabular}{l|c}
\hline Years after construction & 56 \\
\hline Width(W),Height $(\mathrm{H})$, Span length $(\mathrm{S})(\mathrm{mm})$ & $\mathrm{W}=10000, \mathrm{H}=500, \mathrm{~S}=5400$ \\
\hline re-bar & $\mathrm{D} 19$ \\
\hline Strength of concrete & $21 \mathrm{~N} / \mathrm{mm}^{2}$ \\
\hline Strength of reinforcing bar & 235 \\
\hline Live load & $200 \mathrm{kN} * 2$ \\
\hline
\end{tabular}

\section{Deterioration Conditions}

Figure 3 shows diffusion of chloride ion amount at the surface of reinforcing bar, chloride ion amount at the surface of reinforcing bar (span central), and appearance visual observation result. These were calculated by combining chloride ion amounts investigation by electromagnetic wave radar method and fluorescent X-ray method. Figure 4 shows the calculation results of chloride ion amount at the structural surface of span central. This is the calculation result added cover thickness data to Figure 3.

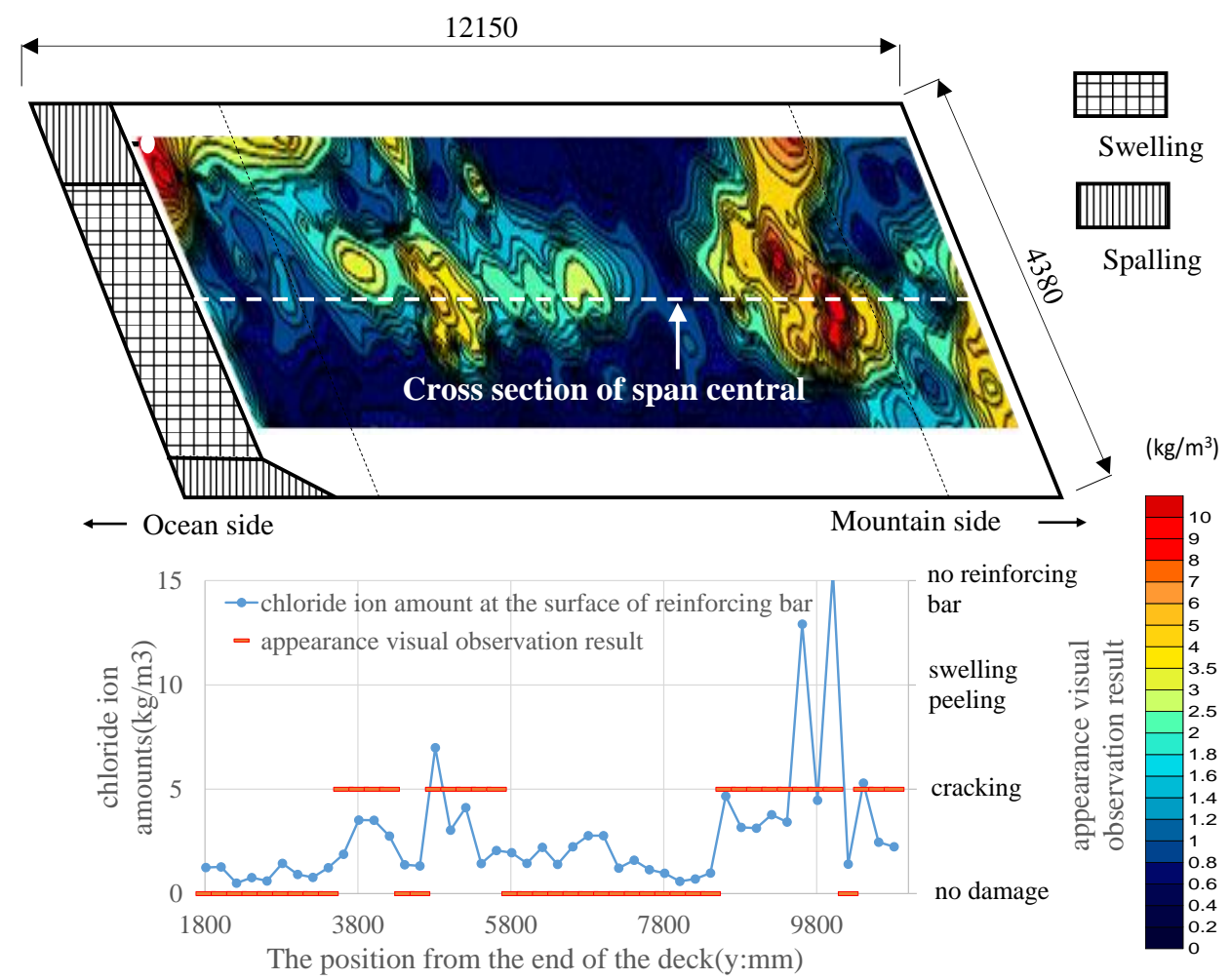

Figure 3. Diffusion of chloride ion amount at the surface of reinforcing bars, Chloride ion amount at the surface of reinforcing bar (Span central), Appearance visual observation result 


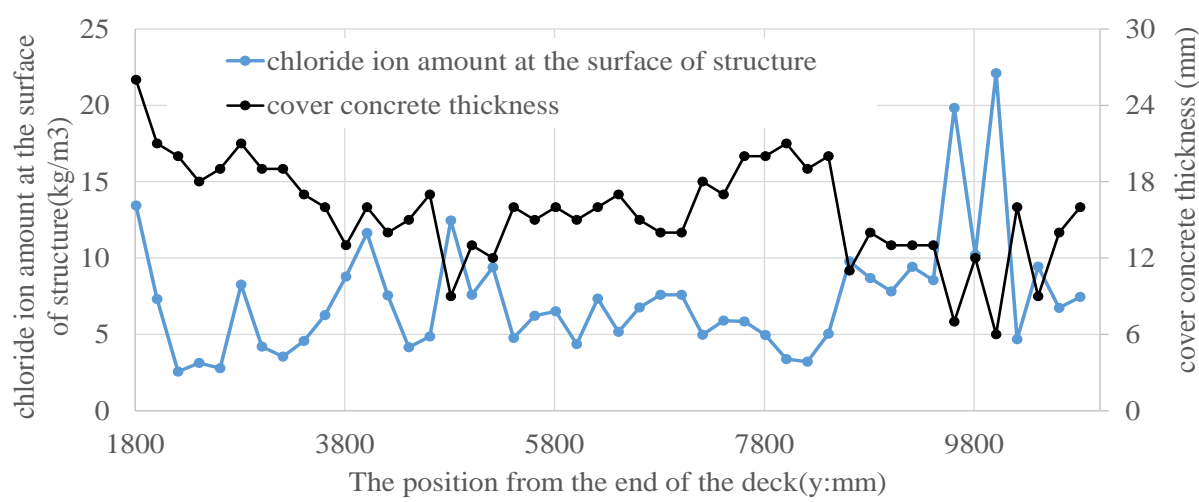

Figure 4. Chloride ion amount at the surface of structure (Center of span), Cover tickness

\section{Prediction of Cross-Sectional Area Variation of Reinforcing Bar}

First, we set a condition group for 300 trials by adding a random variable to the abovementioned conditions, and calculate the cross-sectional reduction amount of every reinforcing bars. The amount of cross-sectional reduction of reinforcing bar is calculated from the construction year to 100 years after construction at an interval 0.2 years. The position of the reinforcing bar is $y=1810 \mathrm{~mm}$ to $11000 \mathrm{~mm}$ from the end of the deck. Figure 5 (a) shows calculation results of cross-sectional area of reinforcing bar at $\mathrm{y}=1810 \mathrm{~mm}$ and $3810 \mathrm{~mm}$. The appearance visual observation result in 57 years is no damage at $y=1810 \mathrm{~mm}$ and cracking at $\mathrm{y}=3810 \mathrm{~mm}$. In Figure 5 (a), red frame shows the range of the cross-sectional area of reinforcing bar matching to the appearance visual observation result. Figure 5 (b) shows the result of extracting it. In the case of application of only the investigation result (Figure 5(a)), the estimate of the cross-sectional of reinforcing bar has a wide range. However, as shown in Figure 5 (b), by matching with the appearance visual result, the width of the cross-sectional area of reinforcing bar estimation could be narrowed. Since the proposed method is a nondestructive method, we cannot calculate specific values, but we can improve accuracy of cross-sectional reduction estimation of reinforcing bar.

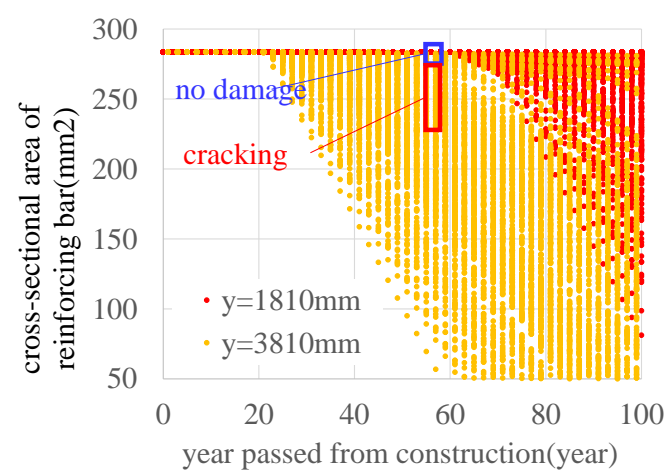

(a) $\mathrm{y}=1810 \mathrm{~mm}$

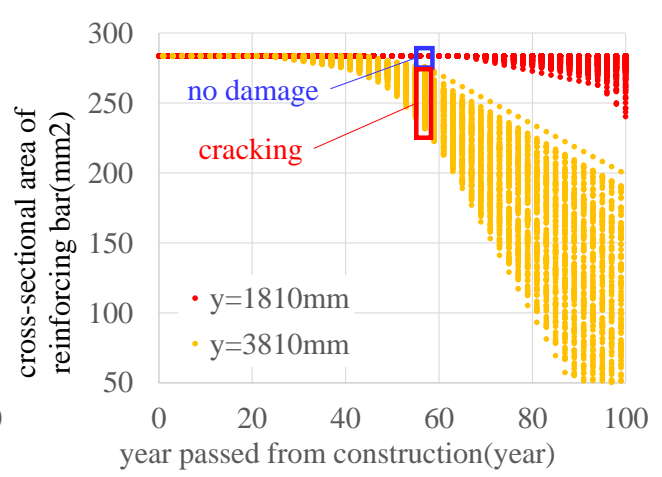

(b) $\mathrm{y}=3810 \mathrm{~mm}$

Figure 5. Prediction result of cross-sectional area variation of reinforcing bar

\section{Monitoring Structural Safety}


Similarly, in all reinforcing bars, we calculate changing in the sectional-area. Next, we calculate load-bearing capacity of bending as structural safety. Among the results, Figure 6 shows the load-bearing capacity of bending at 57 years and 80 years passed from construction. In the conventional method, administrators do not do quantitative evaluation at 57 years, because structure has only cracking. Even if it is implemented, the number of investigation points will be small if administrators have restrictions on cost etc. As a result, it is difficult to grasp the overall trend of degradation of structural safety. However, the results of the structural performance simple evaluation system shows the overall trend of degradation of structural safety. According to Figure 6(a), at 57 years from construction, load-bearing capacity of bending has not degraded. On the other hand, at 80 years from construction, there is a possibility that load-bearing capacity of bending below the limit value may occur at around $\mathrm{y}=4000 \mathrm{~mm}$ and around $10000 \mathrm{~mm}$. That is, the structural performance simple evaluation system can grasp the general tendency of changing about load-bearing capacity easily. Therefore, this system is effective to monitor structural safety.
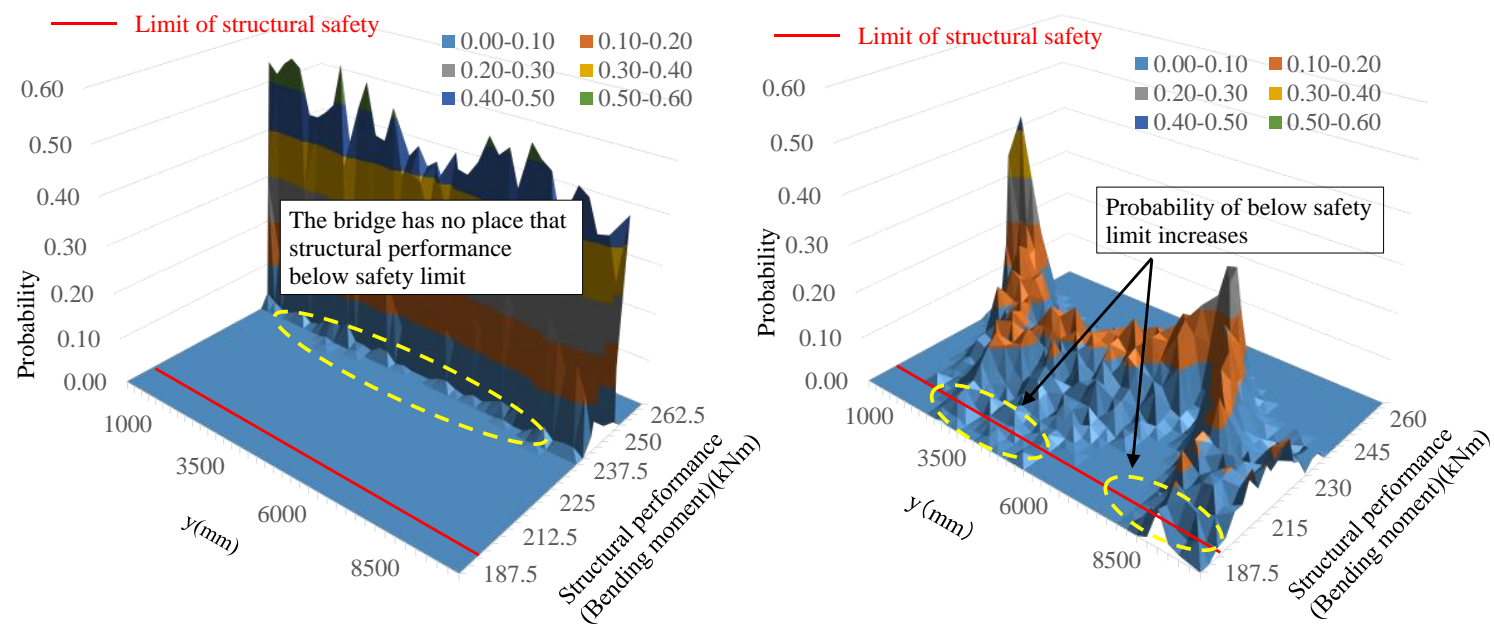

(a) 57 years passed from construction

(b) 80 years passed from construction

Figure 6. Prediction result of load-bearing capacity of bending moment

\section{CONCLUSIONS}

We constructed the system that monitors structural safety with non-destruction in a limited budget and time. The results of this paper are shown below.

- Since the proposed method is a non-destructive method, we cannot calculate specific values, but we can improve accuracy of cross-sectional reduction estimation of reinforcing bar.

- The results of the structural performance simple evaluation system shows the overall trend of degradation of structural safety.

- The structural performance simple evaluation system can grasp the general tendency of changing about load-bearing capacity easily.

- The structural performance simple evaluation system is effective to monitor structural safety. 


\section{REFERENCES}

Japan road association, Specification for highway bridges, part3 concrete bridges (2012)

Japan Society of Civil Engineers, Committee report "Structural Performance of Concrete Structure with Material Deterioration (331)", Japan (2006)

Kinoshita. et al, Degradation prediction method on bending strength of RC members in splash zone, Concrete Research and Technology, Vol.33, No.1, Japan (2011)

Ministry of Land, Infrastructure, Transport and Tourism, Current status of road structure maintenance (2013).

Ministry of Land, Infrastructure, Transport and Tourism, Measures of road aging (2016).

Nojima. et al, Future prediction method of salt damage progression using estimation of chloride ion amounts by electromagnetic wave, Concrete Research and Technology, Vol.35, No.1, Japan (2013)

Watanabe. et al, Prediction of chloride ion amounts using fluorescence X-ray, 2017 JSCE annual meeting, Japan (2017) 